\begin{tabular}{|l|l|}
\hline $\begin{array}{l}\text { Postprint } \\
\text { Version }\end{array}$ & 1.0 \\
\hline Journal website & http://vb23.bsl.nl/BSL/content/nav/0168-9428/inh/inh.htm \\
\hline Pubmed link & \\
\hline DOI & \\
\hline
\end{tabular}

This is a NIVEL certified Post Print, more info at http://www.nivel.eu

\title{
Het placebo-effect in de huisartsenpraktijk: communicatie als medicijn
}

\author{
W. VERHEUL, J.M. BENSING ${ }^{1}$ \\ ${ }^{1}$ Drs. W. Verheul, promovendus, Nederlands instituut voor onderzoek van de \\ gezondheidszorg NIVEL, Utrecht. \\ Mevrouw prof.dr. J.M. Bensing, directeur, Nederlands instituut voor onderzoek van de \\ gezondheidszorg NIVEL, Utrecht; hoogleraar, Gezondheidspsychologie, Faculteit Sociale \\ Wetenschappen, Universiteit Utrecht.
}

\begin{abstract}
SAMENVATTING
Er is groeiend empirisch bewijs dat conditioneringsprocessen, het manipuleren van verwachtingen en de reductie van negatieve gevoelens een placebo- (of nocebo-)effect in werking kunnen zetten. De arts-patiëntcommunicatie biedt mogelijkheden om deze mechanismen te beïnvloeden. Het is voor de effectiviteit van de behandeling van belang dat huisartsen zich bewust zijn van deze mechanismen en de werking ervan proberen in te schatten. Zij kunnen doelgerichte communicatie hierbij op verschillende manieren als instrument gebruiken.
\end{abstract}

\section{INLEIDING}

Iedere huisarts kent het intrigerende verschijnsel dat patiënten kunnen opknappen van een behandeling zonder dat daar een objectieve reden voor is. Een pilletje zonder werkzame bestanddelen, een met overtuiging gebracht huis- tuin- en keukenadvies, een geruststellend schouderklopje, ze doen soms wonderen. Het heeft weinig met wetenschap te maken en staat in geen enkele richtlijn of standaard, maar het werkt wel. Welke huisarts kan daar geen prachtige anekdotes over vertellen?

Het verschijnsel waarnaar hier verwezen wordt, is in de literatuur bekend onder de naam 'placebo-effect'. Dit effect is zo oud als de geneeskunde zelf, maar werd in de loop van de tijd wel heel verschillend gewaardeerd. Lange tijd is het helend vermogen van de arts in de literatuur beschreven als een waardevol en kostbaar element van de geneeskunst (the art of medicine), vanaf het laatste kwart van de twintigste eeuw is geleidelijk steeds meer nadruk komen te liggen op de geneeskunde (the science of medicine) en daarmee op de technocratische kanten van het medisch handelen. De term 'placebo-effect' is in diskrediet geraakt in deze tijd van evidence-based geneeskunde. Onder het motto dat 'wat niet bewezen kan worden geen plaats verdient in de medische zorg' werd en wordt het placebo-effect in grote delen van de medische literatuur genegeerd, gebagatelliseerd of verguisd. Maar het 
Verheul, W., Bensing, J.M. Het placebo-effect in de huisartsenpraktijk: communicatie als medicijn. Bijblijven: 2008, 24(2), 38-44

risico bestaat dat het kind met het badwater wordt weggegooid. Tenslotte worden patiënten op grote schaal beter van dat loze pilletje, het met overtuiging gebrachte advies of het vriendelijke schouderklopje! Gelukkig is er de laatste tijd - onder andere dankzij de opkomst van beeldvormende technieken - ook binnen de wetenschappelijke wereld weer meer aandacht ontstaan voor de rol van placebo-effect in de geneeskunde. Er zijn theorieën ontwikkeld over de werkzame mechanismen achter het placebo-effect en er is een stroom van empirisch onderzoek op gang gekomen (met name binnen de neurocognitieve wetenschappen) dat steeds een stukje van de legpuzzel blootlegt. Het laatste woord over hoe het placebo-effect werkt is nog lang niet gezegd, maar het is wel tijd om nu een tussenstand te rapporteren zodat praktiserend huisartsen er hun voordeel mee kunnen doen. Daarbij concentreren we ons op de rol die de communicatie tussen huisarts en patiënt speelt in dit proces: communicatie als medicijn.

\section{DE HISTORIE VAN HET PLACEBO-EFFECT}

Het is belangrijk om een onderscheid te maken tussen de begrippen 'placebo' en 'placeboeffect'. Het Latijnse placebo betekent letterlijk: 'Ik zal behagen'. De term verwijst naar het feit dat de arts een behandeling voorschrijft die geen specifieke werkzaamheid heeft, puur om de patiënt een dienst te bewijzen. Zo'n behandeling kan een broodpil zijn of een suikerpil, een gekleurd drankje, een injectie met een zoutoplossing of zelfs een schijnoperatie waarbij alleen een incisie wordt gemaakt. Kortom, iedere medische interventie zonder specifieke werkzaamheid is in feite een placebo.

Het 'placebo-effect' is het gezondheidseffect dat patiënten ervaren als gevolg van een behandeling die op zichzelf geen bekende helende werking heeft, maar toch een positieve invloed. Het gaat dan vooral om de wijze waarop en de condities waaronder de behandeling wordt toegepast, en om factoren in de relatie tussen arts en patiënt. Kortom, het gaat om het effect van de psychologische, sociale en culturele context van de behandeling (witte jas, warme dokter, imponerende apparatuur), die vertrouwen of hoop oproepen. ${ }^{1}$ In de literatuur wordt in dit verband ook wel gesproken over contextfactoren of aspecifieke factoren.

Placebo's worden al sinds het begin van de geneeskunde zowel bewust als onbewust toegepast door artsen. Bewust, in het geval van angstige of veeleisende patiënten of om hoop te bieden bij gebrek aan een effectieve behandeling. Ook werden placebo's soms bewust toegepast als testcase, om na te gaan of de ziekte van de patiënt wel 'echt' was en niet psychosomatisch. En tot slot had het voorschrijven van een placebo soms ook een symbolische of rituele functie. Onder het motto: 'Baat het niet dan schaadt het niet' kon een consult op een voor patiënt en arts bevredigende manier worden afgesloten.

Terugkijkend op de medische geschiedenis blijkt dat placebo's ook (vaak onbewust) door artsen zijn toegepast. Er zijn talloze voorbeelden van behandelingen waarvan men ooit dacht dat ze effectief waren, terwijl later uit onderzoek bleek dat zij geen of zelfs een schadelijke werking hadden. Medische handboeken uit de vorige eeuw bevatten honderden behandelingen die met de kennis van nu alleen maar als placebo beschouwd kunnen worden. ${ }^{2}$ In 1993 is een groot aantal onderzoeken naar de effectiviteit van deze inmiddels obsolete interventies opnieuw geanalyseerd. Hoewel de interventies in alle gevallen objectief niet werkzaam waren, werden toch bij $40 \%$ van de 6931 betrokken patiënten excellente resultaten gerapporteerd; bij 30\% een goed resultaat en in slechts 30\% een slecht resultaat. ${ }^{3}$ De auteurs concluderen dat wanneer niet alleen de patiënt maar ook de arts gelooft in de behandeling die wordt voorgeschreven, de invloed van de zogeheten aspecifieke factoren veel groter is dan gewoonlijk wordt aangenomen.

Uit een aantal reviews blijkt dat placebo-effecten veel voorkomen, zowel bij psychische, psychosomatische als somatische aandoeningen. Placebo-effecten zijn aangetoond bij de ziekte van Parkinson, hypertensie, verkoudheid, bronchitis, herpes simplex, reumatoïde artritis, depressie, angststoornissen, chronische pijn en vele andere aandoeningen.

Desondanks heeft het placebo-effect in de loop van de geschiedenis een slechte naam 
gekregen. Het verschijnsel herinnert aan de premoderne geneeskunde en wordt daarom maar liever vergeten. ${ }^{4}$ De associatie met alternatieve geneeswijzen en kwakzalverij heeft al evenmin bijgedragen aan de acceptatie ervan. Alleen in de onderzoeksmethodologie heeft de term 'placebo' een gerespecteerde plaats behouden, maar alleen om het effect te kunnen controleren, niet om het te benutten.

Recent is er in wetenschappelijke kringen opnieuw aandacht ontstaan voor het placeboeffect. Dit keer met de uitdrukkelijke bedoeling de mechanismen achter het placebo-effect beter te leren begrijpen, zodat die kennis ten goede kan komen aan de medische zorg. Het gaat dan in feite om de extra effecten die bovenop de effecten van de eigenlijke behandeling komen en niet om schijnbehandelingen zoals de klassieke placebo. Daarbij wordt verwezen naar factoren in de arts-patiëntrelatie en naar de communicatie tussen arts en patiënt. ${ }^{5,6}$ Het placebo-effect wordt gedefinieerd als het effect op de gezondheid dat voortkomt uit de nietspecifieke aspecten van de behandeling, oftewel: uit de context van de behandeling. Hoe belangrijk die context is, blijkt uit onderzoeken waarin een behandeling openlijk dan wel verborgen plaatsvindt. Onder andere Colloca en collega's ${ }^{7}$ hebben zulk onderzoek uitgevoerd. Aan patiënten met postoperatieve pijn werd morfine toegediend, ofwel door een arts die vertelde dat hij een krachtige pijnstiller toediende ofwel door een automatische pomp zonder dat de patiënt zich daarvan bewust was. In het laatste geval was er 50\% meer morfine nodig om hetzelfde pijnstillende effect te bewerkstelligen. Bovendien kwam het pijnstillende effect veel minder snel tot stand. Een zelfde effect werd gezien bij toediening van diazepam tegen toestandsangst: in de verborgen conditie leidde toediening niet tot vermindering van de angst, in de open conditie wel. ${ }^{7}$ Een groot deel van de werkzaamheid van medicatie hangt dus af van hoe een arts met de patiënt communiceert.

Het is belangrijk te beseffen dat dergelijke contextuele factoren ook negatieve effecten kunnen hebben. Men noemt dit het nocebo-effect ('Ik zal schaden'). Vaak gaat het hierbij om bijwerkingen: wanneer bijvoorbeeld als bijwerking van aspirine gastro-intestinale klachten worden genoemd, dan worden deze klachten ook vaker ervaren. ${ }^{8}$ Net als het placebo-effect berust ook het nocebo-effect niet alleen op subjectieve zelfrapportage. Dit blijkt bijvoorbeeld uit een onderzoek waarin men een zoutoplossing injecteerde bij patiënten met een voedselallergie, met de mededeling dat de injectie allergenen bevatte: $25 \%$ van de subjecten ontwikkelde een allergische reactie. ${ }^{9}$

In een groeiend aantal empirische onderzoeken heeft men de laatste jaren diverse placeboeffecten zichtbaar weten te maken in de fysiologie en vooral de hersenactiviteit van patiënten. ${ }^{5,6,10}$ Deze harde bevindingen hebben als breekijzer gefungeerd voor een hernieuwde erkenning van het placebo-effect als relevant fenomeen in de gezondheidszorg. In plaats van het placebo-effect te zien als ruis waarvoor gecontroleerd dient te worden, zien steeds meer wetenschappers dit effect als een interessant wetenschappelijk probleem dat met moderne (beeldvormende) technieken bestudeerd kan worden en dat wellicht concrete mogelijkheden biedt om de zorg te verbeteren. Daartoe moet men in de eerste plaats zicht krijgen op de werkzame mechanismen in het placebo-effect. Als we de placebomechanismen in de arts-patiëntcommunicatie beter begrijpen, kunnen we ze doelbewust inzetten om de kwaliteit en effectiviteit van de zorg evidence-based te verbeteren. Dan hoeft de art of medicine niet langer op basis van louter intuïtie te worden beoefend maar krijgt zij een serieuze wetenschappelijke basis.

\section{Werkzame mechanismen in het placebo-effect}

Er is veel discussie over de precieze mechanismen die leiden tot het placebo-effect. Dit komt onder andere omdat de context van de behandeling kan ingrijpen op meerdere mechanismen, en die zowel separaat als simultaan kan activeren. De mechanismen die in de placeboliteratuur het meest worden genoemd zijn:

a) conditionering, b) het scheppen van verwachtingen en c) de reductie van stress of negatieve gevoelens. ${ }^{1}$ 
a) Conditionering treedt op wanneer tegelijkertijd met een werkzame stimulus $\mathrm{A}$ een andere, neutrale stimulus B wordt toegediend. Onbewust vindt dan in de hersenen van de betrokkene een koppeling plaats die ervoor zorgt dat op stimulus B de reactie volgt die oorspronkelijk bij stimulus A hoorde, ook zonder dat stimulus A wordt toegediend. Drinkt een patiënt bijvoorbeeld een aantal keren een gekleurd drankje waarin een stof is opgelost die het immuunsysteem onderdrukt, dan wordt het immuunsysteem óók onderdrukt als de patiënt een identiek gekleurd drankje drinkt waaraan de betreffende stof niet is toegevoegd. ${ }^{11}$ Een bekend klinisch voorbeeld is de patiënt die jaren na de succesvolle afsluiting van een zware chemokuur nog altijd misselijk wordt wanneer zij langs het ziekenhuis fietst waar zij indertijd de kuur heeft ondergaan.

b) Het scheppen van verwachtingen bereikt een bepaald effect juist omdat de patiënt verwacht dat het effect zal optreden. Dit mechanisme wordt door veel empirisch onderzoek ondersteund. ${ }^{12}$ Waarschijnlijk spelen lichaamseigen opiaten als endorfine en dopamine een rol in dit proces. Dit kan worden afgeleid uit het feit dat een door verbale suggesties geïnduceerd placebo-effect op postoperatieve pijn ongedaan gemaakt kan worden wanneer er naloxon (een opiaatantagonist) wordt toegediend. ${ }^{13}$ De betrokkenheid van het opiatensysteem in de hersenen werd verder ondersteund door recent onderzoek met beeldvormende technieken. ${ }^{14}$ In dit onderzoek bleek dat patiënten die van hun arts te horen kregen dat hen een krachtig pijnstillend middel werd toegediend op precies dezelfde locatie hersenactiviteit ontwikkelden als patiënten die de pijnstiller daadwerkelijk kregen.

c) Negatieve gevoelens (stress, angst et cetera) spelen een rol bij allerlei lichamelijke klachten, zoals vegetatieve klachten en klachten aan het bewegingsapparaat. ${ }^{15}$ Ook het immuunsysteem wordt beïnvloed door stress. ${ }^{16}$ Daar komt bij dat gezondheidsklachten weer kunnen leiden tot extra stress, zodat er gemakkelijk een vicieuze cirkel ontstaat. Het reduceren van stress of negatieve gevoelens kan deze spiraal ombuigen. Zo vond men in een groep patiënten met het prikkelbaredarmsyndroom placebo-effecten op pijn die niet werden gemedieerd door het endorfinesysteem maar door vermindering van negatieve emoties. ${ }^{17}$ Dit zou het gevolg kunnen zijn van de daarmee gepaard gaande sympathische activiteit. ${ }^{18}$ Een andere mogelijke verklaring voor de placebo-effecten van vermindering van negatieve emotie wordt geboden door de disruptietheorie. ${ }^{10}$ In een onderzoek waarin men pijnpatiënten de verwachting gaf dat pijnverlichting zou optreden, bleek het oproepen van emotionele aspecten van de pijn een placebo-effect te veroorzaken. De verwachting beïnvloedde met name de mate waarin de pijn door de patiënt als vervelend werd ervaren.

Voor elk van de hier genoemde mogelijke mechanismen achter het placebo-effect bestaat harde empirische evidentie. Soms lijken er meerdere mechanismen tegelijkertijd te werken, bijvoorbeeld wanneer de arts verwachtingen wekt op een warme, vertrouwenwekkende manier ${ }^{18}$ of wanneer patiënten zich ervan bewust worden hoe zij in het verleden door bepaalde ervaringen in de gezondheidszorg zijn geconditioneerd. ${ }^{20}$

\section{DE ROL VAN COMMUNICATIE IN HET PLACEBO-EFFECT}

Vrijwel alle reviews over het placebo-effect zijn het erover eens dat de communicatie tussen arts en patiënt een belangrijke rol speelt in de totstandkoming van placebo- en overigens ook nocebo-effecten in de gezondheidszorg., ${ }^{5,6,12}$ Toch zijn er maar weinig klinische onderzoeken gedaan naar het vermogen van specifieke communicatie-elementen om een placebo-effect te bewerkstelligen; communicatie wordt meestal opgevat als containerconcept. Er valt op basis van de besproken mechanismen echter wel iets te zeggen over de vraag hoe communicatie tussen arts en patiënt een rol kan spelen bij de totstandkoming van placebo-effecten. Men zal hiertoe eerst moeten analyseren hoe de drie mechanismen door de arts beïnvloed kunnen worden. 
Verheul, W., Bensing, J.M. Het placebo-effect in de huisartsenpraktijk: communicatie als medicijn. Bijblijven: 2008, 24(2), 38-44

\section{Conditionering}

Alle patiënten dragen op het moment dat ze de spreekkamer binnenstappen vroegere ervaringen met zich mee die - dankzij de reeds besproken conditioneringsprocessen positief maar ook negatief kunnen bijdragen aan het genezingsproces. Dit kan ertoe leiden dat patiënten anders reageren op de medische behandeling dan je op grond van de medische literatuur zou verwachten. $\mathrm{Nu}$ is conditionering per definitie een automatisch proces, waarvan de patiënt zich niet bewust hoeft te zijn. Daarom doen artsen er goed aan zich in zo'n geval te realiseren dat er geconditioneerde placebo- of nocebo-effecten in het spel kunnen zijn. Heeft een patiënt bijvoorbeeld in het verleden pillen voorgeschreven gekregen die als bijwerking misselijkheid hadden, dan zou conditionering ervoor kunnen zorgen dat dezelfde bijwerking optreedt bij andere medicatie, die er hetzelfde uitziet maar waarbij men deze bijwerking helemaal niet zou verwachten. ${ }^{21}$ Als een behandeling dus niet de verwachte resultaten oplevert, is het raadzaam om door te vragen naar eerdere ervaringen van de patiënt en deze bespreekbaar te maken. Als patiënten zich eenmaal bewust zijn van hun geconditioneerde responsen, kan dat helpen om het nocebo-effect te verminderen of zelfs teniet te doen. Meer onderzoek hiernaar is noodzakelijk.

\section{Verwachtingen}

Artsen kunnen met hun communicatie de verwachtingen van de patiënt beïnvloeden. Dat dit ook invloed heeft op de gezondheidsstatus van de patiënt, blijkt onder andere uit het klassieke gerandomiseerde onderzoek van een Engelse huisarts bij patiënten met medisch onverklaarde klachten, gepubliceerd onder de titel 'Is there any point in being positive?" ${ }^{19}$ De helft van deze patiënten kreeg een (onwerkzaam) pilletje mee, de andere helft niet. Binnen elke groep kreeg de helft van de proefpersonen positieve, geruststellende informatie en de andere helft neutrale informatie. Het interessante is dat er inderdaad een placebo-effect optrad met betrekking tot de ervaren klachten, maar dat dit effect het sterkst was bij de patiënten die positieve communicatie hadden ontvangen. Een pilletje zonder positieve communicatie had geen effect op de ervaren gezondheid. Dit betekent twee dingen. In de eerste plaats is het belangrijk dat een arts zich ervan vergewist wat de patiënt verwacht van de voorgeschreven behandeling, aangezien deze verwachtingen zowel een positieve als een negatieve invloed kunnen hebben (dit is overigens ook van belang met het oog op therapietrouw). Ten tweede onderschrijft het de noodzaak van een goede uitleg aan de patiënt over het effect van de behandeling. Die uitleg moet dus niet alleen uit ethische overwegingen gegeven worden, maar ook omdat het een klinisch relevante invloed kan hebben op de uitkomst van de behandeling.

Overigens roept dit tweede aspect voor de arts ook ethische dilemma's op. Hoe specifiek moet je zijn over de mogelijke bijwerkingen van een geneesmiddel als je weet dat de patiënt deze bijwerkingen daardoor eerder zal ervaren? Mag je patiënten ongefundeerde optimistische informatie geven over de voorgeschreven behandeling als je denkt dat ze zich daardoor beter gaan voelen? Of is het juist onethisch om de kracht van het placebo-effect niet op deze manier te benutten? Er bestaat een spanningsveld tussen enerzijds de toegenomen vraag naar autonomie en het zelfs in de Wet op de geneeskundige behandelingsovereenkomst vastgelegde recht van de patiënt op goede en complete informatie, en anderzijds de kansen die de arts heeft om door het scheppen van de juiste verwachtingen de gezondheid van de patiënt positief te beïnvloeden.

Hoe verschillend men kan denken over dit soort ethische dilemma's bleek toen een van de auteurs van dit artikel dit dilemma voorlegde aan twee verschillende groepen mensen: leden van een patiëntenvereniging en derdejaars psychologiestudenten. De eerste groep was eensgezind van mening dat patiënten onder geen enkele voorwaarde misleid mogen worden. Het bewust creëren van een placebo-effect door ongefundeerde positieve verwachtingen te wekken geeft volgens deze actieve patiënten blijk van gebrek aan respect. Men voelt zich niet serieus genomen. Heel anders reageerden de studenten. Op basis van de overweldigende hoeveelheid empirische literatuur over de omvang van het placebo-effect bij de meest 
uiteenlopende ziekten meenden deze dat een arts patiënten wel degelijk zou mogen misleiden als dat een positief gezondheidseffect zou hebben.

Er is dus geen pasklaar antwoord op deze vragen, die de huisarts telkens opnieuw moet beantwoorden. Belangrijk is het in ieder geval om de eigen integriteit te bewaken. Immers, vertrouwen speelt een belangrijke rol in de totstandkoming van placebo-effecten. ${ }^{22} \mathrm{Als}$ patiënten zich misleid of bedrogen voelen door hun arts, zal dit onvermijdelijk eventuele placebo-effecten teniet doen en zelfs een nocebo-effect kunnen hebben. Overigens moet men bedenken dat de arts de verwachtingen van de patiënt slechts dan kan manipuleren wanneer de patiënt de arts vertrouwt. ${ }^{18}$ Een warme, vriendelijke arts die meeleeft met de patiënt zal hierin eerder slagen dan een koude afstandelijke arts. ${ }^{19}$

\section{Reductie van stress of negatieve gevoelens}

Er is veel bekend van de invloed van negatieve gevoelens op het beloop van ziekte. Minder bekend is dat ook de gang naar de dokter voor veel patiënten al een stressvolle gebeurtenis is. ${ }^{23}$ Alleen daarom al is het belangrijk om stress te verminderen en de patiënt expliciet op zijn gemak te stellen. Bij het verminderen van negatieve gevoelens speelt natuurlijk mee welk ziektebeloop de arts verwacht. Het gaat dan om dezelfde factoren als die hierboven zijn behandeld. Maar hoe dan ook kan de arts het stressniveau van de patiënt verlagen door op een warme, vriendelijke en empathische manier te communiceren. Een heel mooi voorbeeld is te vinden in een een onderzoek van Fogarty en medewerkers. ${ }^{24} \mathrm{Zij}$ maakten een videoopname van een oncologisch consult in twee exact gelijke versies. Aan één conditie voegden zij veertig extra seconden toe, waarin de arts aan het begin en het eind van het consult enkele empathische opmerkingen maakte. De video's werden getoond aan twee gerandomiseerde groepen mensen (overlevenden van kanker en proefpersonen uit de algemene bevolking). In beide groepen waren de mensen die de empathische consulten hadden gezien minder angstig dan de mensen die het neutrale consult hadden gezien. Dit onderzoek toont aan dat relatief simpele en makkelijk toepasbare elementen in de communicatie tussen arts en patiënt waarin de huisartsen in het algemeen ook goed getraind is - ertoe kunnen bijdragen dat de patiënt zich beter gaat voelen.

\section{CONCLUSIE}

Na de bijna vergeten slogan van de Engelse psychiater Balint uit de jaren vijftig, the doctor as the drug, wordt het nu tijd voor een nieuw elan: 'communicatie als medicijn'. Dit elan vindt ondersteuning in de snel groeiende empirische literatuur naar de fysiologische basis van het placebo-effect. Conditioneringsprocessen, het manipuleren van verwachtingen en de reductie van negatieve gevoelens kunnen een placebo- (of nocebo-)effect in werking zetten. De arts-patiëntcommunicatie biedt mogelijkheden om deze mechanismen te beïnvloeden. Het is voor de effectiviteit van de behandeling van belang dat huisartsen zich bewust zijn van deze mechanismen en de werking ervan proberen in te schatten. Zij kunnen doelgerichte communicatie hierbij op verschillende manieren als instrument gebruiken. Wanneer conditioneringseffecten de reden zijn dat een behandeling niet het verwachte effect heeft, kan de arts dergelijke conditioneringsprocessen aan de patiënt uitleggen en ze daarmee bespreekbaar en hanteerbaar maken. Ook het doelbewust scheppen van positieve verwachtingen kan een positief effect hebben op het ziekteverloop en het gemak waarmee vervelende behandelingen worden ondergaan, onder andere doordat de patiënt meer vertrouwen krijgt in de eigen competentie om met de situatie om te gaan. ${ }^{12}$ Hierbij gelden uiteraard bepaalde ethische grenzen: de vertrouwensrelatie mag niet op het spel worden gezet. Net zo belangrijk is het, negatieve gevoelens bij de patiënt te verminderen door op een warme, empathische manier te communiceren.

Er is nog veel onderzoek nodig naar de precieze uitwerking van verschillende elementen in de arts-patiëntcommunicatie op de subjectieve en objectieve gezondheidstoestand van de 
Verheul, W., Bensing, J.M. Het placebo-effect in de huisartsenpraktijk: communicatie als medicijn. Bijblijven: 2008, 24(2), 38-44

patiënt. Het bestaande placebo-onderzoek geeft echter al wel een duidelijke richting aan.

Wanneer op deze wijze meer evidence beschikbaar komt over de effecten van communicatie - niet als containerbegrip maar uitgesplitst naar verschillende werkzame elementen in verschillende medische situaties - krijgt communicatie hopelijk de plaats die zij verdient in onderzoek, scholing en praktijk: als wellicht het krachtigste instrument dat huisartsen tot hun beschikking hebben.

\section{LITERATUUR}

1. Dulmen AM van, Bensing JM. The effect of context in health care: A programming study. RGO, Den Haag, 2001.

2. Shapiro AK, Shapiro E. The Placebo: is it much ado about nothing? In: Harrington A, editor. The placebo-effect: An interdisciplinary exploration. Cambridge (MA): Harvard University Press, 1997.

3. Roberts AH, Kewman DG, Mercier L, Hovell M. The power of nonspecific effects in healing: Implications for psychosocial and biological treatments. Clin Psychol Rev 1993;13:375-91.

4. Wampold BE, Imel ZE, Minami T. The story of placebo effects in medicine: Evidence in context. J Clin Psychol 2007;63:379-90.

5. Di Blasi Z, Harkness E, Ernst E, Georgiou A, Kleijnen J. Influence of context effects on health outcomes: A systematic review. Lancet 2001;357:757-62.

6 . Benedetti F. How the doctor's words affect the patient's brain. Eval Health Prof 2002;25:369-86.

7. Colloca L, Lopiano L, Lanotte M, Benedetti F. Overt versus covert treatment for pain, anxiety, and Parkinson's disease. Lancet Neurol 2004;3:679-84.

8. Myers MG, Cairns JA, Singer J. The consent form as a possible cause of side effects. Clin Pharmacol Ther 1987;42:250-3.

9. Jewett DL, Fein G, Greenberg MH. A double-blind study of symptom provocation to determine food sensitivity. N Engl J Med 1990;323:429-33.

10. Lieberman MD, Jarcho JM, Berman S, Naliboff BD, Suyenobu BY, Mandelkern M, et al. The neural correlates of placebo effects: A disruption account. Neuroimage 2004;22:44755.

11. Goebel MU, Trebst AE, Steiner J, Xie YF, Exton MS, Frede S, et al. Behavioral conditioning of immunosuppression is possible in humans. FASEB J 2002;16:1869-73.

12. Crow R, Gage H, Hampson S, Hart J, Kimber A, Thomas $H$. The role of expectancies in the placebo effect and their use in the delivery of health care: A systematic review. Health Technol Assess 1999;3:1-96.

13. Levine JD, Gordon NC, Fields HL. The mechanism of placebo analgesia. Lancet 1978;2:654-7.

14. Petrovic $P$, Kalso E, Petersson KM, Ingvar M. Placebo and opioid analgesia: Imaging a shared neuronal network. Science 2002;295:1737-40.

15. Ursin $\mathrm{H}$, Eriksen $\mathrm{H}$. Cognitive activation theory of stress, sensitization, and common health complaints. Ann N Y Acad Sci 2007;1113:304-10.

16. Cohen S, Frank E, Doyle WJ, Skoner DP, Rabin BS, Gwaltney JM Jr. Types of stressors that increase susceptibility to the common cold in healthy adults. Health Psychol 1998;17:214-23.

17. Vase L, Robinson ME, Verne GN, Price DD. Increased placebo analgesia over time in irritable bowel syndrome (IBS) patients is associated with desire and expectation but not endogenous opioid mechanisms. Pain 2005;115:338-47.

18. Pollo A, Vighetti S, Rainero I, Benedetti F. Placebo analgesia and the heart. Pain 2003;102:125-33.

19. Thomas KB. General practice consultations: Is there any point in being positive? Br Med J (Clin Res Ed) 1987;294:1200-2.

20. Stewart-Williams S, Podd J. The Placebo Effect: Dissolving the Expectancy

VersusConditioning Debate. Psychological Bulletin2004Vol. 130, No. 2, 324-340

21. Barsky AJ, Saintfort R, Rogers MP, Borus JF. Nonspecific medication side effects and the nocebo phenomenon. JAMA 2002;287:622-7. 
Verheul, W., Bensing, J.M. Het placebo-effect in de huisartsenpraktijk: communicatie als medicijn. Bijblijven: 2008, 24(2), 38-44

22. Hall MA, Dugan E, Zheng B, Mishra AK. Trust in physicians and medical institutions: What is it, can it be measured, and does it matter? Milbank Q 2001;79:613-39.

23. Ben-Sira, Z. Affective and instrumental components in the physician-patient relationship: An additional dimension of interaction theory. J Health Soc Behav 1980;21:170-80.

24. Fogarty LA, Curbow BA, Wingard JR, McDonnell K, Somerfield MR. Can 40 seconds of compassion reduce patient anxiety?J Clin Oncol 1999;17:371-9. 